University of Wollongong

Research Online

Faculty of Engineering and Information

Faculty of Engineering and Information

Sciences - Papers: Part A

Sciences

$1-1-2016$

Elastomeric and dynamic MnO2/CNT core-shell structure coiled yarn supercapacitor

Changsoon Choi

Hanyang University

Hyeon Jun Sim

Hanyang University

Geoffrey M. Spinks

University of Wollongong, gspinks@uow.edu.au

Xavier Lepró

University of Texas

Ray H. Baughman

University of Texas, ray.baughman@utdallas.edu

See next page for additional authors

Follow this and additional works at: https://ro.uow.edu.au/eispapers

Part of the Engineering Commons, and the Science and Technology Studies Commons

Research Online is the open access institutional repository for the University of Wollongong. For further information contact the UOW Library: research-pubs@uow.edu.au 


\title{
Elastomeric and dynamic MnO2/CNT core-shell structure coiled yarn supercapacitor
}

\author{
Abstract \\ Reversibly deformable and highly performing solid-state yarn supercapacitors are obtained using \\ MnO2-deposited microcoiled yarn electrodes. The core(CNT)-shell(MnO2)-structured coiled electrodes \\ achieve high stretchability (37.5\%) without the help of elastomeric substrates, minimizing the size of the \\ supercapacitors. Therefore, high specific capacitances of $34.6 \mathrm{~F} \mathrm{~cm}-3,61.25 \mathrm{mF} \mathrm{cm}-2$, and $2.72 \mathrm{mF}$ \\ $\mathrm{cm}-1$ are achieved for coiled supercapacitors without impairing mechanical stretchability or \\ electrochemical cyclability. \\ Disciplines \\ Engineering | Science and Technology Studies

\section{Publication Details} \\ Choi, C., Sim, H. Jun., Spinks, G. M., Lepró, X., Baughman, R. H. \& Kim, S. Jeong. (2016). Elastomeric and \\ dynamic $\mathrm{MnO}_{2} / \mathrm{CNT}$ core-shell structure coiled yarn supercapacitor. Advanced Energy Materials, 6 (5), \\ 1502119-1-1502119-8.

\section{Authors} \\ Changsoon Choi, Hyeon Jun Sim, Geoffrey M. Spinks, Xavier Lepró, Ray H. Baughman, and Seon Jeong \\ Kim
}




\section{WILEY-VCH}

DOI: $10.1002 /(($ please add manuscript number))

\section{Article type: Communication}

\section{Elastomeric and Dynamic $\mathrm{MnO}_{2} / \mathrm{CNT}$ Core-Shell Structure Coiled Yarn Supercapacitor}

Changsoon Choi, Hyeon Jun Sim, Geoffrey M. Spinks, Xavier Lepro, Ray H. Baughman and Seon Jeong Kim*

C. Choi, H. J. Sim, Prof. S. J. Kim

Center for Self-powered Artificial Muscle and Department of Biomedical Engineering, Hanyang University, Seoul 133-791, Korea, [*] E-mail: sjk@ hanyang.ac.kr

Prof. G. M. Spinks,

Intelligent Polymer Research Institute, ARC Centre of Excellence for Electromaterials Science, University of Wollongong, Wollongong, NSW 2522, Australia.

Dr. X. Lepro, Prof. R. H. Baughman

The Alan G. MacDiarmid Nano Tech Institute, University of Texas at Dallas, Richardson, TX, 75083, USA.

Keywords: Coil, Stretchable, $\mathrm{MnO}_{2}$, Carbon nanotube, Supercapacitor 


\section{WILEY-VCH}

One-dimensional (1-D) yarn/fiber supercapacitors are more attractive power sources than conventional three- or two-dimensional (3-D, 2-D) foam/film-type when they are used for miniaturized electronic devices, textile electronics, and implantable medical devices ${ }^{1}$ because their small volume and high flexibility enable them to be easily integrated into the devices with a tiny size and various shapes. Nevertheless, most fiber-based supercapacitors (FBSs) simply possess the flexibility with limited tensile strain and stretchability ${ }^{2-16}$ because they are mostly based on nonstretchable electrodes such as carbon nanotube (CNT) spun yarn, ${ }^{2-7}$ graphene fiber, ${ }^{8-12}$ carbon fiber, ${ }^{13,14}$ and metal wire. ${ }^{15}$ This lack of stretchability of these FBSs leads to limitation for more advanced utilization, e.g., as a power source for artificial muscles ${ }^{17}$ or wearable devices that are exposed to high strain, especially in the joint part. ${ }^{18}$ In recent years, several strategies have been reported to incorporate stretchability into FBSs: CNT sheet nanomembranes were wound onto elastic fibers to make highly stretchable FBSs $^{19-21}$ or CNT fiber electrodes were attached onto prestrained elastic fibers to form a micro-buckling structure for FBSs. ${ }^{22,23}$ Although these FBSs exhibited stable stretchability and energy storage performances, they still suffer from low electrochemical energy storage performance because the additional core fibers used as elastomeric substrates do not participate in electrochemical energy storage reactions but merely provide stretchability, resulting in low gravimetric and volumetric energy storage performances of the total devices. ${ }^{24}$ To solve these problems, novel spring-like stretchable CNT fibers were proposed as supercapacitor electrodes. ${ }^{24}$ It is notable that stretchability could be achieved for the first time in FBSs by using the spring CNT fiber without the help of any elastomeric substrate. However, the spring-based supercapacitors still showed limited capacitances because their active material was based on pristine CNT, totally depending on the electrochemical double layer capacitance (EDLC) energy storage mechanism. All things considered, achieving FBSs 


\section{WILEY-VCH}

possessing not only stretchability but also excellent specific capacitances remains challenging.

In this study, we present coil structured, pseudocapacitive yarns as promising electrodes for achieving stretchable and highly performing supercapacitors. The bare CNT coiled yarns are fabricated by inserting a giant twist (50,000 twists/m) into CNT spun yarns, which are drawn from a multiwalled carbon nanotube (MWNT) forest. ${ }^{25}$ Although the bare CNT coiled yarns can be used as stretchable electrodes for EDLC-based supercapacitor without further processing, ${ }^{24}$ we deposited $\mathrm{MnO}_{2}$, which is a promising pseudocapacitive material because of its high theoretical capacitance, low cost, and environmental friendliness ${ }^{26}$ to enhance dramatically its energy storage capacity. A scanning electron microscope (SEM) image of the our novel core $(\mathrm{CNT})-\operatorname{shell}\left(\mathrm{MnO}_{2}\right)$ structured hybrid coiled yarn is shown in Figure 1A. The diameter of the single hybrid coiled electrode is $\sim 80 \mu \mathrm{m}$ and about 200 uniform microloops are contained in a centimeter of coiled electrode. The resulting aspect ratio (ratio of coiled electrode's length to diameter) is high (about 210) and the electrode volume is impressively small $\left(\sim 6.5 \times 10^{-5} \mathrm{~cm}^{3}\right)$ that the volume of presented coiled CNT electrode is one-twentieth the size of previously reported coiled CNT/nylon fiber ${ }^{21}$.

A high-resolution SEM surface image of the bare CNT coiled yarn (Figure 1B) shows closely packed and uniaxially aligned CNT bundles, which implies an effective electron pathway for longitudinal current collecting. After the $\mathrm{MnO}_{2}$ deposition (Figure 1C), a mesoporous film, which is morphologically characteristic of $\mathrm{MnO}_{2},{ }^{27}$ is uniformly formed on the surface of the coiled electrode. It is experimentally confirmed that strong adhesion of the $\mathrm{MnO}_{2}$ thin shell to the porous CNT surface is achieved so that high electrochemical stability could be demonstrated against repeated mechanical deformation by loop opening or electrochemical reaction, which will be discussed later. In this study, the mass of $\mathrm{MnO}_{2}$ was 


\section{WILEY-VCH}

measured using an electrochemical quartz-crystal microbalance (EQCM). From the slope of the charge-mass graph measured by EQCM, the mass of $\mathrm{MnO}_{2}$ per unit charge transferred during deposition is determined to be $5.4 \times 10^{-4} \mathrm{~g} \mathrm{C}^{-1}$, as shown in Figure S1. To measure the thickness of the $\mathrm{MnO}_{2}$ shell layer, cross-sectional analysis was performed by cutting the hybrid coiled electrode along its diameter using a Ga ion beam, as shown in Figure 1D. Figure 1E shows a magnified SEM image of the denoted rectangle at the edge part of the hybrid coiled yarn cross-section shown in Figure 1D. The nanoscopic $\mathrm{MnO}_{2}$ shell with thickness $\sim 1$ $\mu \mathrm{m}$ is distinguished from the CNT core part. Because only nanoscopic surfaces of $\mathrm{MnO}_{2}$ can participate in the electrochemical energy storage reaction, the loading amount of $\mathrm{MnO}_{2}$ is controlled by adjusting its deposition time to have a thin shell with reasonable thickness $(\sim 1$ $\mu \mathrm{m})$ to obtain high capacitances and high-rate capability, simultaneously. As a consequence, volume and weight fractions of presented $\mathrm{MnO}_{2}$ shell to total hybrid coiled electrode are calculated to be $4.9 \%$ and $17.2 \%$, respectively. This pseudocapacitive micro-shell plays crucial role in enhancing energy storage performances of yarn supercapacitors.

Energy dispersive spectroscopy (EDS) analysis was performed to characterize clearly the hybrid core-shell structure of the electrode. Elemental mapping analysis for $\mathrm{C}, \mathrm{O}$, and $\mathrm{Mn}$ atoms was performed on the Figure 1D image to detect the location of specific atoms, as shown in Figure $\mathbf{2 A}-\mathrm{C}$. The core part of the hybrid coiled electrode has highly densified CNT without any observable pores. This pure CNT core is well distinguished by dominant C atoms' detection (denoted by red dots, Figure 2A) while the shell part is mainly detected by $\mathrm{O}$ atoms (green dots, Figure 2B) and Mn atoms (blue dots, Figure 2C). Clearer identification of atomic core-shell structure can be confirmed through the overlapped $\mathrm{C}, \mathrm{O}, \mathrm{Mn}$ mapping images (Figure S2). Figure 2D indicates X-ray photoelectron spectroscopy (XPS) analysis of the deposited $\mathrm{MnO}_{2}$ film. The binding energy difference between $\mathrm{Mn} 2 \mathrm{p}_{3 / 2}$ and $\mathrm{Mn} 2 \mathrm{p}_{1 / 2}$ 


\section{WILEY-VCH}

peaks is about $11.8 \mathrm{eV}$, which exactly matches the value for $\mathrm{MnO}_{2} \cdot{ }^{28}$ Therefore, it can be concluded that this nonvacuum-based, scalable, and cost-effective electrochemical deposition technique achieves successful core-shell structure formation for stretchable, pseudocapacitive yarn electrodes.

Figure 3A schematically illustrates the configuration of a complete solid-state, stretchable, and highly performing coiled supercapacitor. Two symmetric pseudocapacitive coiled electrodes were assembled in a parallel direction with constant gap and coated with aqueous poly(vinyl alcohol) (PVA)-based gel containing lithium chloride ( $\mathrm{LiCl}$ ) with thickness around $20 \mu \mathrm{m}$. Figure 3B shows cyclic voltammogram (CV) curves of bare coiled $\mathrm{CNT}$ and $\mathrm{MnO}_{2} / \mathrm{CNT}$ core-shell coiled electrodes. Although the $\mathrm{MnO}_{2}$ content is relatively small compared with the total electrode ( $4.9 \%$ volume fraction or $17.2 \%$ weight fraction), it achieves about $512 \%$ capacitance enhancement by the pseudocapacitive effect. Figure 3C shows CV curves of the solid-state coiled yarn supercapacitor measured with scan rates from 10 to $100 \mathrm{mV} \mathrm{s}^{-1}$. The box-like rectangular-shaped $\mathrm{CV}$ curves without any redox peak well represent the pseudocapacitive characteristics of our coiled supercapacitor. The rectangularshaped CV curves could be retained for high scan rates up to $500 \mathrm{mV} \mathrm{s}^{-1}$ (Figure S3), showing high-rate capability. Figure 3D shows the Nyquist curve of the coiled supercapacitor. A vertical curve indicates an excellent capacitive characteristic of the coiled supercapacitor. Moreover, low equivalent series resistance (ESR) as small as $0.07 \Omega \mathrm{cm}^{3}$ is achieved (inset of Figure 3D). To inspect the charge/discharge characteristic of the coiled supercapacitor, galvanostatic curves at current densities of $0.2,0.6$, and $2 \mathrm{~A} \mathrm{~cm}^{-3}$ were measured (Figure S4). Symmetrical triangle-shaped galvanostatic curves show good agreement with Nyquist analysis, indicating the excellent pseudocapacitive characteristics of the coiled supercapacitor. The specific capacitances based on single electrode were calculated from the CV curves as 


\section{WILEY-VCH}

shown in Figure 3E. High volumetric capacitance $\left(C_{\mathrm{V}}, 34.6 \mathrm{~F} \mathrm{~cm}^{-3}\right)$, areal capacitance $\left(C_{\mathrm{A}}\right.$, $\left.61.25 \mathrm{mF} \mathrm{cm}^{-2}\right)$, and linear capacitance $\left(C_{\mathrm{L}}, 2.72 \mathrm{mF} \mathrm{cm}^{-1}\right)$ could be achieved at $10 \mathrm{mV} \mathrm{s}^{-1}$ scan rate. The gravimetric capacitance $\left(C_{\mathrm{M}}\right)$ can be calculated about $26.5 \mathrm{~F} \mathrm{~g}^{-1}$ for the coiled supercapacitor. Dimensions of the total electrodes (both $\mathrm{MnO}_{2} / \mathrm{CNT}$ coiled yarns) were used for normalization of specific capacitance. Moreover, high volumetric and areal energy densities $\left(2.4 \mathrm{mWh} / \mathrm{cm}^{3}\right.$ and $\left.8.5 \mu \mathrm{Wh} / \mathrm{cm}^{2}\right)$ were achieved in our stretchable fiber supercapacitor. The maximum capacitance values at $10 \mathrm{mV} \mathrm{s}^{-1}$ are retained to about $71.6 \%$ at $100 \mathrm{mV} \mathrm{s}^{-1}$ and $39 \%$ at $500 \mathrm{mV} \mathrm{s}^{-1}$, showing high-rate capability (Figure S3).

Specific capacitances of the coiled supercapacitors are compared with other FBSs in Table 1. Notably, the coiled supercapacitor exhibited much higher linear and areal capacitances $\left(2.72 \mathrm{mF} \mathrm{cm}^{-1}, 61.25 \mathrm{mF} \mathrm{cm}^{-2}\right)$ than reported stretchable FBSs based on buckled CNT fiber $\left(0.26 \mathrm{mF} \mathrm{cm}^{-1}, 27.98 \mathrm{mF} \mathrm{cm}^{-2}\right)^{23}$ and CNT spring fiber $\left(0.51 \mathrm{mF} \mathrm{cm}^{-1}, 27.07 \mathrm{mF}\right.$ $\left.\mathrm{cm}^{-2}\right)^{24}$ as shown in Table 1. It should be noted that the volumetric capacitance of the presented coiled supercapacitor $\left(34.6 \mathrm{~F} \mathrm{~cm}^{-3}\right)$ was also excellent that about 10 times higher than our previous research on nylon fiber based stretchable supercapacitor $\left(3.8 \mathrm{~F} \mathrm{~cm}^{-3}\right)^{21}$ without sacrificing linear and areal capacitances. These high specific capacitances were originated from effectively minimized volume of pristine CNT based coiled fibers (only 5.2\% volume of previous stretchable fiber $)^{21}$ by not using any elastomeric substrates. Moreover, the observed specific capacitances are remarkably higher than other reported hybrid FBSs, which do not offer the benefits of reversible elastomeric deformability. For example, the volumetric capacitance of our coiled supercapacitor $\left(34.6 \mathrm{~F} \mathrm{~cm}^{-3}\right)$ is about 14 times higher than $\mathrm{MnO}_{2} /$ carbon FBS $\left(2.5 \mathrm{~F} \mathrm{~cm}^{-3}\right)^{13}$ and 7 times higher than $\mathrm{MoS}_{2}$-reduced graphene oxide/CNT FBS $\left(4.8 \mathrm{~F} \mathrm{~cm}^{-3}\right)^{7}$. Moreover, its linear capacitance $\left(2.72 \mathrm{mF} \mathrm{cm}^{-1}\right)$ is two orders higher than $\mathrm{MnO}_{2} / \mathrm{CNT}$ FBS $\left(0.019 \mathrm{mF} \mathrm{cm}^{-1}\right)^{2}, \mathrm{MnO}_{2} / \mathrm{ZnO}$ nanowire-coated $\mathrm{FBS}\left(0.02 \mathrm{mF} \mathrm{cm}^{-1}\right)^{13}$ and 


\section{WILEY-VCH}

also significantly higher than $\mathrm{CNT} /$ reduced graphene oxide fiber $\left(0.35 \mathrm{mF} \mathrm{cm}^{-1}\right)^{11}$. Such high specific capacitances of our coiled supercapacitor compared with other FBSs can be attributed to the following two aspects. The first is that nanoscopic, mesoporous, and pseudocapacitive metal oxide coating effectively enables high energy storage performance, without sacrificing the high-rate capability or mechanical stretchability. Second, neither additional elastomeric substrate nor separator is used in our coiled supercapacitor system, dramatically minimizing the total dimension of the electrodes.

Figure 4A shows optical images of the complete coiled supercapacitor before and after $37.5 \%$ strain was applied. Although the theoretical maximum strain is much higher for coiled CNT yarn (about more than $300 \%$ strain, which originates from the relation $L$ (coiled yarn length $) \approx l($ initial yarn length $) / \pi),{ }^{29}$ we present $37.5 \%$ as the maximum strain for a coiled supercapacitor. Because the applied strain rate for static tests in this study is much faster (180 $\mathrm{mm} \min ^{-1}$ or $\left.2 \% \mathrm{~s}^{-1}\right)$ than the literature ${ }^{29}\left(0.5 \mathrm{~mm} \mathrm{~min}^{-1}\right.$ strain rate, 15 minute intermediate stress relaxation every strain increment) that not enough relaxation time is provided to uniformly relax the generated internal stresses during stretching and this results in early fracture for the coiled yarn ( $40 \%$ in tensile strain). In spite of such an early fracture, we adopted high strain rates $\left(2-6 \% \mathrm{~s}^{-1}\right.$ or $180-540 \mathrm{~mm} \mathrm{~min}^{-1}$ for dynamic tests) based stretching tests to reflect the real circumstances of wearable applications. The size of the tested supercapacitor was so small that it looks like a thin single thread to the naked eye, as shown in Figure 4A. Mechanical strain loading/unloading cycles were performed by applying tensile strains from $20 \%$ to $40 \%$ with sequentially $5 \%$ increments to the hybrid coiled electrode (Figure 4B). It is notable that the coiled electrode can be stretched up to $40 \%$ and reversibly recovered without significant residual deformation (less than 2.5\%). This stretchable electrode's mechanical reversibility has not been reported among other stretchable FBSs. ${ }^{19-24}$ 


\section{WILEY-VCH}

In addition, the constant slopes of the loading curves exhibit high modulus from $290(\varepsilon=$ $20 \%)$ to $325 \mathrm{MPa}(\varepsilon=40 \%)$, while hysteretic energy dissipations by the recovery friction force were observed during unloading. ${ }^{29}$ The capacitance retention of the coiled supercapacitor under mechanically static strain $\left(2 \% \mathrm{~s}^{-1}\right)$ is characterized by comparing its $\mathrm{CV}$ curves before and after 37.5\% strain was applied, as shown in Figure 4C. Figure 4D shows static capacitance retention with a strain range from $20 \%$ to $40 \%$ before the coiled yarn breaks. The coiled supercapacitor exhibits about $84 \%$ capacitance retention at the maximum strain of $37.5 \%$. This capacitance drop can be attributed to a linear resistance increase of the coiled electrode when it gets stretched. ${ }^{29}$ The inset shows SEM images of microloops before and after $37.5 \%$ stretching, showing reversible intercoil distance change.

Based on target applications of power source for wearable electronics, it is necessary to characterize the dynamic electrochemical performance ${ }^{30}$ of stretchable supercapacitor by measuring real-time capacitance retention under dynamically applied strain. To guarantee reliable elasticity with negligible residual deformation, the following dynamic characterizations were performed with a moderate strain of $20 \% .^{29}$ Figure 5A-C show dynamically measured CV curves of the coiled supercapacitor with various strain rates. Applied strain rates of 2,4 , and $6 \% \mathrm{~s}^{-1}$ can be converted into frequencies of $0.1,0.2$, and 0.3 $\mathrm{Hz}$ for a stretching, respectively, which are close to that of human motion-based movements $(0.67-4 \mathrm{~Hz}){ }^{31}$ In the static mode, the coiled supercapacitor can retain $90 \%$ capacitance at 20\% strain and reversibly recovered its initial capacitance when released (Figure S5). Therefore, dynamic capacitance variation (capacitance decrease during yarn stretching and recovery during releasing) results in dynamic $\mathrm{CV}$ curves with an uneven contour during the tests (Figure $5 \mathrm{~A}-\mathrm{C}$ ). Because it takes $10 \mathrm{~s}$ for the coiled supercapacitor to reach $20 \%$ strain at $2 \% \mathrm{~s}^{-1}$ strain rate (Figure 5A), a single stretching/releasing cycle is included per CV cycle 


\section{WILEY-VCH}

measured at $100 \mathrm{mV} \mathrm{s}^{-1}$ scan rate. Similarly, two and three stretching/releasing cycles are included per $\mathrm{CV}$ cycle at 4 and $6 \% \mathrm{~s}^{-1}$ strain rates, respectively (Figure $5 \mathrm{~B}$ and Figure $\mathrm{C}$ ). The resulting dynamic capacitance retentions at various strain rates are summarized in Figure 5D. Owing to highly adhesive $\mathrm{MnO}_{2}$ shell formation on the yarn electrode, structural stability, and stable ion supply by the gel electrolyte of the coiled supercapacitor, it exhibits $95.5,96.2$, and $96.3 \%$ dynamic capacitance retention at 2,4 , and $6 \% \mathrm{~s}^{-1}$ strain rates without any electrical short-circuit or significant performance degradation.

To characterize the reliability of electrochemical performances of the coiled supercapacitor, repeated stress loading/unloading and charge/discharge cycles were independently conducted. With a moderate strain of $20 \%$, the coiled supercapacitor showed capacitance retentions of $95 \%$ after 1000 stretching/releasing cycles and $98.8 \%$ after 1000 charge/discharge cycles (Figure S6A). Good adhesion between the $\mathrm{MnO}_{2}$ shell and CNT core can be also confirmed through SEM images (Figure S6B). After the cycle tests, the $\mathrm{MnO}_{2}$ shell still remains in a well-attached state over the whole electrode without any observable detachment or cracks. On the other hand, the $\mathrm{MnO}_{2}$ shell deposited onto the smooth surface carbon fiber shows significant detachment after the cycle tests, implying poor adhesion to the electrode (Figure S7). This is because the unique surface and internal porosities of twist spun-based CNT yarn ${ }^{32}$ have advantages to have good adhesion with active material. Therefore, this simple way for nanoscopic $\mathrm{MnO}_{2}$ deposition effectively provides strong adhesion to the surface of the bare coiled electrode as well as enhancing the energy storage performance without impairing mechanical stretchability or electrochemical cyclability.

In summary, we have reported stretchable and highly performing yarn-based supercapacitors that use unique core-shell-structured coiled electrodes. Pseudocapacitive core $(\mathrm{CNT})-$ shell $\left(\mathrm{MnO}_{2}\right)$ structured yarns were prepared using an electrochemical method and 


\section{WILEY-VCH}

the resulting solid-state coiled supercapacitor exhibits high elasticity, specific capacitances, and mechanical, electrochemical cyclabilities. The linear and volumetric capacitances of the coiled supercapacitor were $2.72 \mathrm{mF} \mathrm{cm}^{-1}$ and $34.6 \mathrm{~F} \mathrm{~cm}^{-3}$, respectively. About $84 \%$ static capacitance was retained when it was reversibly stretched by $37.5 \%$ in strain while $96.3 \%$ dynamic capacitance was retained during $20 \%$ strain deformation despite the extremely high strain rate of $6 \% \mathrm{~s}^{-1}$. Owing to the active material's strong adhesion and structural stability of the coiled electrode, the coiled supercapacitor exhibited $95 \%$ and $98.8 \%$ capacitance retentions after stretching/releasing and charge/discharge cycles, respectively. Because we have deployed the twist-insertion-based coiling method to obtain a highly elastomeric electrode, the presently described supercapacitor fabrication method can be extended to other diverse high-strength monofilament and multifilament polymer fibers (such as polyethylene, Kevlar, silver-plated nylon, polyester, polypropylene, and poly(vinylidene difluoride)) to make supercapacitors that operate at high temperatures and use either hydrophilic or hydrophobic electrolytes. 


\section{WILEY-VCH}

\section{Experimental Section}

CNT forests $(\sim 400 \mu \mathrm{m}$ high and consisting of $\sim 12 \mathrm{~nm}$ diameter nanotubes containing $\sim 9$ walls) were synthesized using the chemical vapor deposition (CVD) method according to a previous report. $^{25}$ Ten layers of $120 \mathrm{~mm}$ (length) $\times 10 \mathrm{~mm}$ (width) sized CNT sheets were drawn from the forest and stacked on the glass substrate by ethanol evaporation-based densification. One end of the stacked sheet was connected to the electrical motor for coil twisting. The bare CNT coiled yarn electrodes were fabricated by inserting a giant twist ( 50,000 twisting per meter) into CNT sheets. The prepared coiled yarn was electrically connected to $180 \mu \mathrm{m}$ diameter $\mathrm{Cu}$ wire using silver paste for $\mathrm{MnO}_{2}$ deposition and electrochemical performance characterization. The electrochemical $\mathrm{MnO}_{2}$ deposition on the pristine CNT coiled yarn was performed using a potentiostatic method of applying $1.3 \mathrm{~V}$ (vs $\mathrm{Ag} / \mathrm{AgCl}$ as reference electrode and $\mathrm{Pt}$ mesh as counter electrode) in the three electrode of CHI 627b system ( $\mathrm{CH}$ Instruments, Austin, TX) in an electrolyte containing $0.02 \mathrm{M}$ $\mathrm{MnSO}_{4} \cdot 5 \mathrm{H}_{2} \mathrm{O}$ and $0.2 \mathrm{M} \mathrm{Na}_{2} \mathrm{SO}_{4}$ (all chemical products were purchased from Sigma Aldrich). Deposition time for one deposition segment was $3 \mathrm{~s}$ and the number of segments was controlled to adjust the deposition amount. The mass of the $\mathrm{MnO}_{2}$ was measured using EQCM and calculated using the Sauerbrey equation. ${ }^{33}$ The PVA-LiCl gel electrolyte was prepared using $3 \mathrm{~g}$ PVA $\left(\mathrm{M}_{\mathrm{w}} 146,000-186,000\right)$ and $6 \mathrm{~g} \mathrm{LiCl}$ in $30 \mathrm{ml}$ deionized water. The mixture was heated at $90{ }^{\circ} \mathrm{C}$ until it became transparent. Two symmetric $\mathrm{MnO}_{2} / \mathrm{CNT}$ coreshell structured coiled electrodes were placed in a parallel direction with a small gap $(\sim 20$ $\mu \mathrm{m})$ and finally coated with the PVA-LiCl gel electrolyte to complete the fabrication of the coiled supercapacitor. All chemical reagents for solid-electrolyte synthesis were purchased from Sigma Aldrich and used without further processing. To characterize the hybrid coreshell structure of the coiled electrode, cross-sections of the coil were prepared by cutting them 


\section{WILEY-VCH}

along their diameters using a Ga ion beam (7 nA beam current) in a Focused Ion Beam (FIB, Nova 200) operated at $30 \mathrm{kV}$. Then, the cut areas were cleaned via $\mathrm{Ga}$ ion polishing by etching several micrometers of yarn length with consecutively decreasing ion beam-currents ranging from 5.0 to $0.3 \mathrm{nA}$. The cleaned-cut yarns were next transferred to a Zeiss Supra 40 SEM to perform the microscopy (at $15 \mathrm{kV}$ ) and elemental EDAX mapping analysis (at 20 $\mathrm{kV}$ ). Clear views of the yarn's cross-sections were attained by orienting the yarn's cut plane parallel to the electron-beam final aperture/detector in the SEM. Other SEM images were obtained by FE-SEM (S4700, Hitachi). The oxidation state of the $\mathrm{MnO}_{2}$ deposit was characterized by XPS analysis (VG Multilab ESCA 2000 system). All static electrochemical measurements on the coiled supercapacitor utilized a two-electrode configuration with electrochemical analyzer (CHI 627b, CH Instruments). Dynamic CV curves were measured $\left(100 \mathrm{mV} \mathrm{s}^{-1}\right)$ while the coiled supercapacitor was stretched and released at strain rates of 2, 4, and $6 \% \mathrm{~s}^{-1}$ (which can be converted into 180 to $540 \mathrm{~mm} \mathrm{~min}^{-1}$ ). A specially constructed machine for applying tensile deformations was used. The length of the supercapacitor was measured using a digital Vernier caliper (500 series, Mitutoyo), which was incorporated into the stretching machine. Stress loading-unloading curves were obtained using a mechanical analyzer (TMA, SS7100). The volumetric capacitance of the coiled supercapacitor was calculated from the $\mathrm{CV}$ curves. From $C=I /(\mathrm{d} V / \mathrm{d} t)$, where $I$ is the discharge current, the single-electrode specific capacitance $\left(C_{\mathrm{sp}}\right)$ was calculated from the following equation. ${ }^{1}$

$$
C_{\mathrm{sp}}\left(\mathrm{F} / \mathrm{cm}^{3}\right)=4 C / \mathrm{Vol}_{\text {electrode }},
$$

where $\mathrm{Vol}_{\text {electrode }}$ is the total volume of the electrochemical active materials of the two electrodes $\left(\mathrm{MnO}_{2} / \mathrm{CNT}\right.$ coiled electrodes for the present work). In a similar way, total length and surface area of the active materials were used for linear and areal capacitance calculations, 


\section{WILEY-VCH}

respectively. The factor of 4 comes from the capacitance of the two-electrode system and the combined volume of the two electrodes. ${ }^{1}$

\section{References}

[1] J. A. Lee, M. K. Shin, S. H. Kim, H. U. Cho, G. M. Spinks, G. G. Wallace, M. D. Lima, X. Lepro, M. E. Kozlov, R. H. Baughman, S. J. Kim, Nat. Comm. 2013, 4, 1970.

[2] J. Ren, L. Li, C. Chen, X. Chen, Z. Cai, L. Qiu, Y. Wang, X. Zhu, H. Peng, Adv. Mater. 2013, 25, 1155 .

[3] T. Chen, L. Qiu, Z. Yang, Z. Cai, J. Ren, H. Li, H. Lin, X. Sun, H. Peng, Angew.Chem. Int. Ed. 2012, 51, 11977.

[4] X. Chen, L. Qiu, J. Ren, G. Guan, H. Lin, Z. Zhang, P. Chen, Y. Wang, H. Peng, Adv. Mater. 2013, 25, 6436.

[5] H. Sun, X. You, J. Deng, X. Chen, Z. Yang, J. Ren, H. Peng, Adv. Mater. 2014, 26, 2868.

[6] B. Wang, X. Fang, H. Sun, S. He, J. Ren, Y. Zhang, H. Peng, Adv. Mater., doi:10.1002/adma.201503441

[7] G. Sun, X. Zhang, R. Lin, J. Yang, H. Zhang, P. Chen, Angew. Chem. 2015, 127, 4734.

[8] Q. Chen, Y. Meng, C. Hu, Y. Zhao, H. Shao, N. Chen, L. Qu, J. Power Sources 2014, 247, 32.

[9] Y. Meng, Y. Zhao, C. Hu, H. Cheng, Y. Hu, Z. Zhang, G. Shi, L. Qu, Adv. Mater. 2013, $25,2326$.

[10] J. Bae, Y. J. Park, M. Lee, S. N. Cha, Y. J. Choi, C. S. Lee, J. M. Kim, Z. L. Wang, Adv. Mater. 2011, 23, 3446.

[11] Y. Ma, P. Li, J. W. Sedloff, X. Zhang, H. Zhang, J. Liu, ACS Nano 2015, 9, 1352. 


\section{WILEY-VCH}

[12] Y. Liang, Z. Wang, J. Huang, H. Cheng, F. Zhao, Y. Hu, L. Jiange, L. Qu, J. Mater. Chem. A, 2015, 3, 2547.

[13] X. Xiao, T. Li, P. Yang, Y. Gao, H. Jin, W. Ni, W. Zhan, X. Zhang, Y. Cao, J. Zhong, L.

Gong, W. C. Yen, W. Mai, J. Chen, K. Huo, Y. L. Chueh, Z. L. Wang, J. Zhou, ACS Nano 2012, 6, 9200 .

[14] D. Yu, S. Zhai, W. Jiang, K. Goh, L. Wei ,X. Chen, R. Jiang, Y. Chen, Adv. Mater. 2015, 27,4895

[15] Y. Fu, X. Cai, H. Wu, Z. Lv, S. Hou, M. Peng, X. Yu, D. Zou, Adv. Mater. 2012, 24, 5716.

[16] J. Bae, M. K. Song, Y. J. Park, J. M. Kim, M. Liu, Z. L. Wang, Angew. Chem. Int. Ed. 2011, 50, 1683.

[17] M. D. Lima, N. Li, M. J. Andrade, S. Fang, J. Oh, G. M. Spinks, M. E. Kozlov, C. S. Haines, D. Suh, J. Foroughi, S. J. Kim, Y. Chen, T. Ware, M. K. Shin, L. D. Machado, A. F. Fonseca, J. D. W. Madden, W. E. Voit, D. S. Galvao, R. H. Baughman, Science 2012, 338, 928.

[18] C. Yan, J. Wang, W. Kang, M. Cui, X. Wang, C. Y. Foo, K. J. Chee, P. S. Lee, Adv. Mater. 2013, 26, 2022.

[19] Z. Zhang, J. Deng, X. Li, Z. Yang, S. He, X. Chen, G. Guan, J. Ren, H. Peng, Adv. Mater. 2014, 27, 356 .

[20] Y. Zhang, W. Bai, X. Cheng, J. Ren, W. Weng, P. Chen, X. Fang, Z. Zhang, H. Peng, Angew. Chem. Int. Ed. 2014, 53, 14564.

[21] C. Choi, S. H. Kim, H. J. Sim, J. A. Lee, A. Y. Choi, Y. T. Kim, X. Lepro, G. M. Spinks, R. H. Baughman, S. J. Kim, Sci. Rep. 2015, 5, 9387. 


\section{WILEY-VCH}

[22] P. Xu, T. Gu, Z. Cao, B. Wei, J. Yu, F. Li, J. H. Byun, W. Lu, Q. Li, T. W. Chou, Adv. Energy Mater. 2014, 4, 1300759.

[23] P. Xu, B. Wei, Z. Cao, J. Zheng, K. Gong, F. Li, J. Yu, Q. Li, W. Lu, J. H. Byun, B. S. Kim, Y. Yan, T. W. Chou, ACS Nano 2015, 9, 6088.

[24] T. Chen, R. Hao, H. Peng, L. Dai, Angew. Chem. Int. Ed. 2015, 54, 618.

[25] M. Zhang, K. R. Atkinson, R. H. Baughman, Science 2004, 306, 1358.

[26] G. Yu, L. Hu, M. Vosgueritchian, H. Wang, X. Xie, J. R. McDonough, X. Cui, Y. Cui, Z. Bao, Nano Lett. 2011, 11, 2905.

[27] X. Dong, X. Wang, J. Wang, H. Song, X. Li, L. Wang, M. B. Chan-Park, C. M. Li, P. Chen, Carbon 2012, 50, 4865.

[28] S. W. Lee, J. Kim, S. Chen, P. T. Hammond, Y. Shao-Horn, ACS Nano 2010, 4, 3889.

[29] Y. Shang, X. He, Y. Li, L. Zhang, Z. Li, C. Ji, E. Shi, P. Li, K. Zhu, Q. Peng, C. Wang, X. Zhang, R. Wang, J. Wei, K. Wang, H. Zhu, D. Wu, A. Cao, Adv. Mater. 2012, 24, 2896.

[30] X. Li, T. Gu, B. Wei, Nano Lett. 2012, 12, 6366.

[31] S. Jung, J. Lee, T. Hyeon, M. Lee, D. H. Kim, Adv. Mater. 2014, 26, 6329.

[32] C. Choi, J. A. Lee, A. Y. Choi, Y. T. Kim, X. Lepro, M. D. Lima, R. H. Baughman, S. J. Kim, Adv. Mater. 2014, 26, 2059.

[33] S. L. Kuo, N. L. Wu, J. Electrochem. Soc. 2006, 153, A1317. 


\section{WILEY-VCH}

\section{Figure Captions}

Figure 1. Overview SEM image of (A) $\mathrm{MnO}_{2} / \mathrm{CNT}$ core-shell structured coiled electrode (scale bar $=50 \mu \mathrm{m})$. Its magnified surface images of $(\mathrm{B})$ before $($ scale bar $=1 \mu \mathrm{m})$ and $(\mathrm{C})$ after $\mathrm{MnO}_{2}$ deposition onto the bare coiled yarn (scale bar $=400 \mathrm{~nm}$ ). Uniaxially aligned bare CNT electrode's surface is covered by mesoporous and nanoscopic $\mathrm{MnO}_{2}$ film after deposition, constructing a core $(\mathrm{CNT})-\operatorname{shell}\left(\mathrm{MnO}_{2}\right)$ structured yarn electrode. Cross-sectional SEM images of (D) $\mathrm{MnO}_{2} / \mathrm{CNT}$ coiled yarn electrode (scale bar $=20 \mu \mathrm{m}$ ) and (E) magnification of the edge part indicated by a square in $\mathrm{D}$ (scale bar $=3 \mu \mathrm{m}$ ). The $\mathrm{MnO}_{2}$ shell is denoted by arrows. Volume and weight ratio of $\mathrm{MnO}_{2}$ shell to total coiled electrode are calculated to be $4.9 \%$ and $17.2 \%$, respectively.

Figure 2. Elemental mapping analysis performed on the coil cross-section area and the location of (A) C (carbon, red dots), (B) O (oxygen, green dots), and (C) Mn (manganese, blue dots) atoms are spotted. (D) XPS analysis on $\mathrm{MnO}_{2}$ shell. The binding energy difference between the $\mathrm{Mn} 2 \mathrm{p}$ doublet peaks is $11.8 \mathrm{eV}$, which corresponds to that expected for $\mathrm{MnO}_{2}{ }^{21}$

Figure 3. (A) Schematic illustration for the complete solid-state coiled supercapacitor, which comprises two symmetric $\mathrm{MnO}_{2} / \mathrm{CNT}$ core-shell coiled electrodes and gel electrolyte. (B) $\mathrm{CV}$ curve comparison before and after $\mathrm{MnO}_{2}$ deposition onto the bare coiled yarn. As a consequence of the pseudocapacitive contribution of the nanoscopic $\mathrm{MnO}_{2}$ shell, the $\mathrm{CV}$ area increased by about $512 \%$ after $\mathrm{MnO}_{2}$ deposition. (C) $\mathrm{CV}$ curves of solid-state coiled supercapacitor measured from 10 to $100 \mathrm{mV} \mathrm{s}^{-1}$ scan rates. (D) Nyquist curve shows a low ESR value of $0.07 \Omega \mathrm{cm}^{-3}$ around a high frequency of $100 \mathrm{kHz}$ (inset) and vertical line. (E) Calculated volumetric and linear capacitances of solid-state coiled supercapacitor for various 


\section{WILEY-VCH}

scan rates. The highest volumetric and linear capacitances (based on the dimensions of both $\mathrm{MnO}_{2} / \mathrm{CNT}$ coiled electrodes) are $34.6 \mathrm{~F} \mathrm{~cm}^{-3}$ and $2.72 \mathrm{mF} \mathrm{cm}^{-1}$ at $10 \mathrm{mV} \mathrm{s}^{-1}$ scan rate, respectively.

Figure 4. (A) Optical images of solid-state coiled supercapacitor before and after application of $37.5 \%$ tensile strain. The initial length of as-used coiled supercapacitor is $16.8 \mathrm{~mm}$ for the stretching test. Inset shows magnified coiled supercapacitor, which was assembled using two parallel coiled electrodes with a constant gap $(\sim 20 \mu \mathrm{m}$ gap, scale bar $=100 \mu \mathrm{m})$. (B) Stress loading/unloading curves of the hybrid $\mathrm{MnO}_{2} / \mathrm{CNT}$ coiled electrode with tensile strains from $20 \%$ to $40 \%$. (C) Static CV curve comparison before (black line) and after $37.5 \%$ strain applied (red line) to the coiled supercapacitor, showing 84\% capacitance retention. (D) Capacitance retention versus static strain. The inset shows magnified SEM images of microloops before and after $37.5 \%$ strain applied (scale bar $=50 \mu \mathrm{m})$.

Figure 5. Dynamically measured CV curves (at $100 \mathrm{mV} \mathrm{s}^{-1}$ scan rate) during $20 \%$ strain stretching/releasing cycles with various strain rates. Nonstretched $(\varepsilon=0)$ coiled supercapacitor's CV curves are denoted for comparison (black line), while the dynamically measured $\mathrm{CV}$ curves with strain rates of (A) $2 \% \mathrm{~s}^{-1}$ (green line, $10 \mathrm{~s}$ for full stretching), (B) $4 \% \mathrm{~s}^{-1}$ (blue line, $5 \mathrm{~s}$ for full stretching), and (C) $6 \% \mathrm{~s}^{-1}$ (red line, $3.3 \mathrm{~s}$ for full stretching) are presented. (D) Overall dynamic capacitance retentions of a coiled supercapacitor, showing $95.5 \%, 96.2 \%$, and $96.3 \%$ retentions at 2,4 , and $6 \% \mathrm{~s}^{-1}$ strain rates, respectively, after three charge/discharge cycles. 


\section{WILEY-VCH}
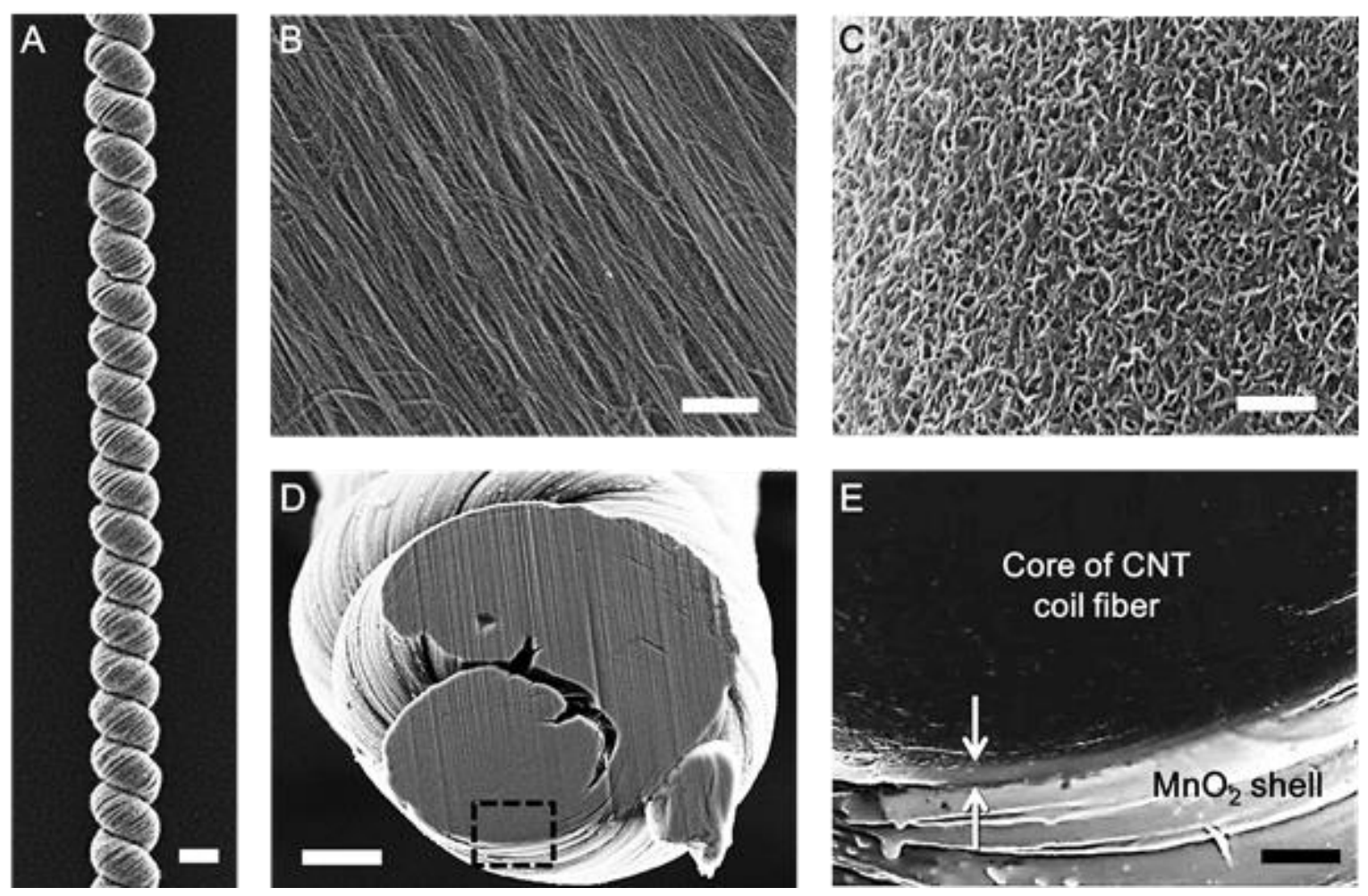

Figure 1 


\section{WILEY-VCH}
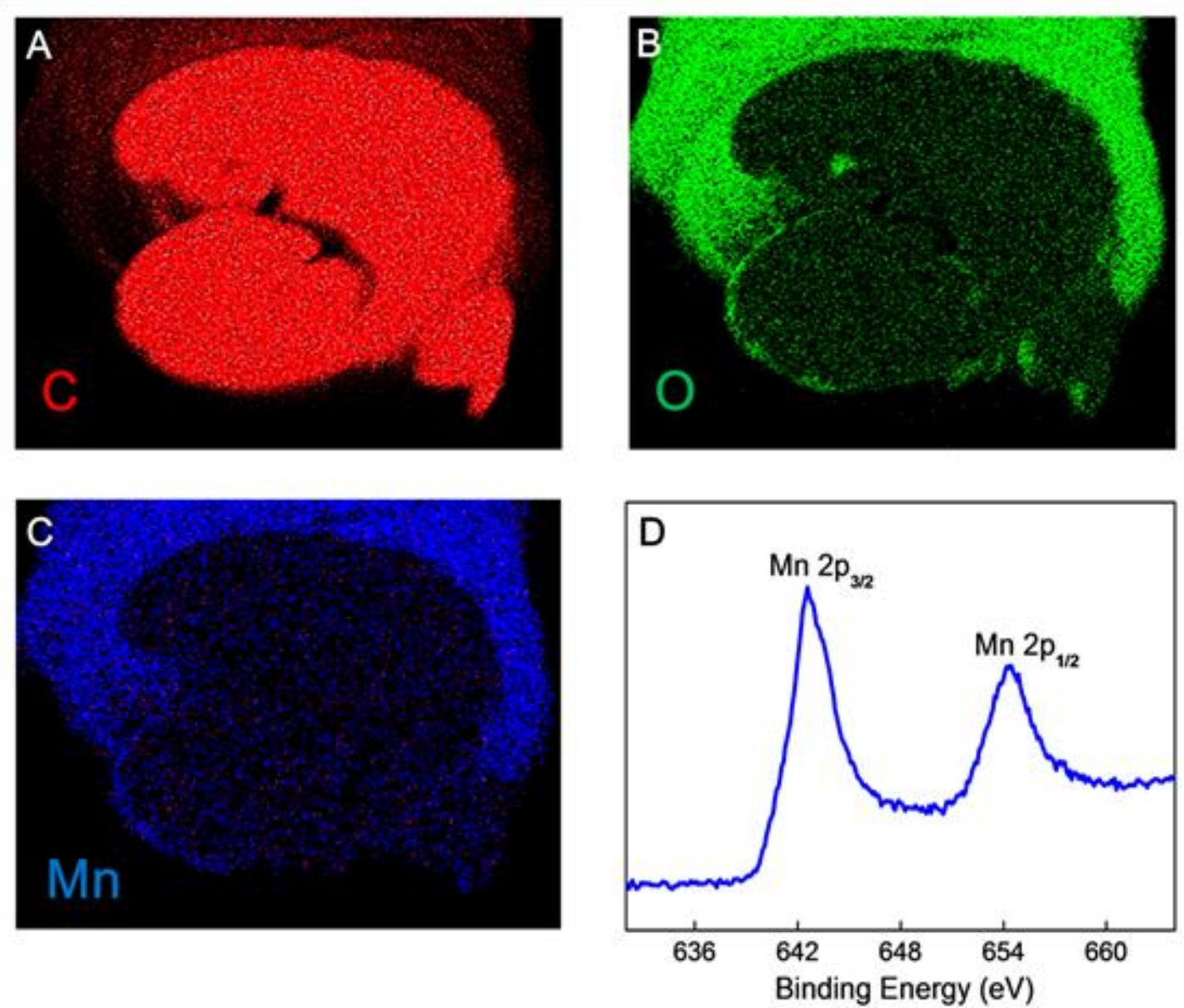

Figure 2 
WILEY-VCH

A

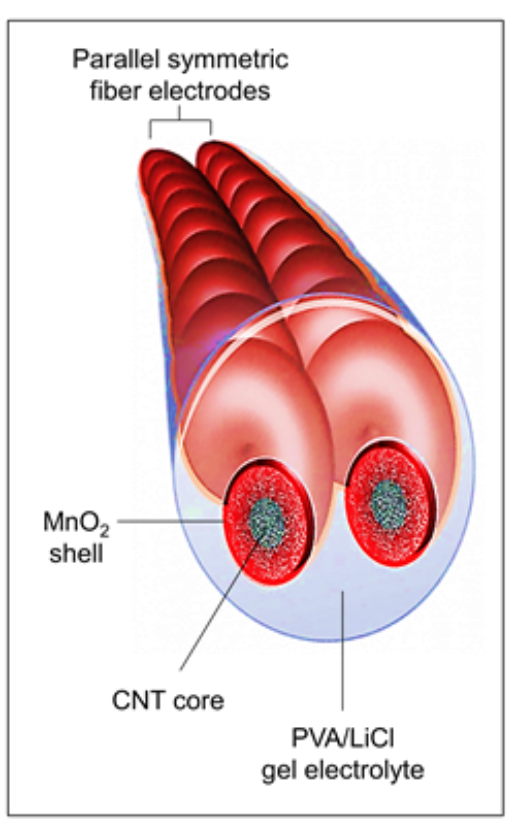

D

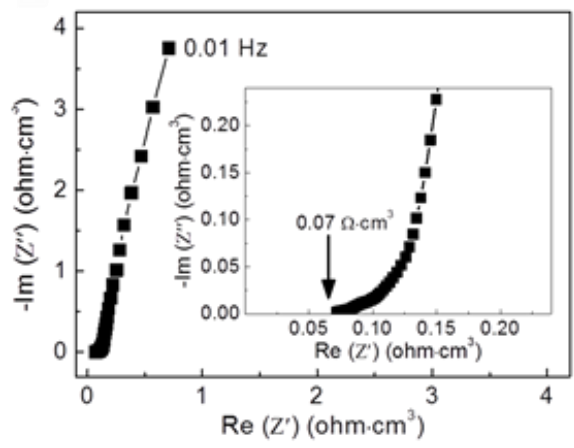

B

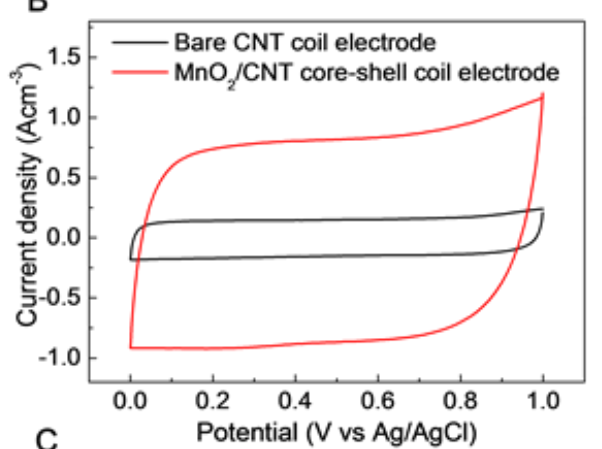

C

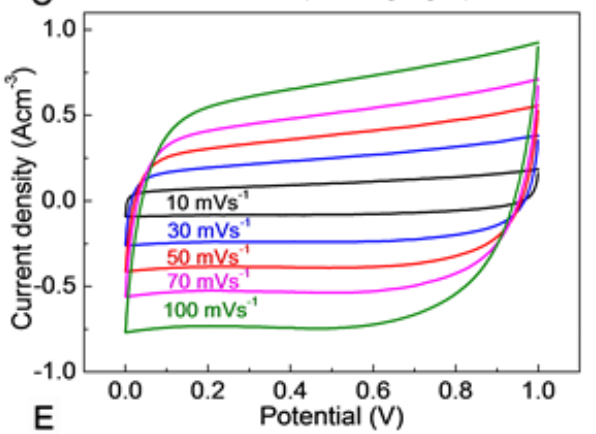

E

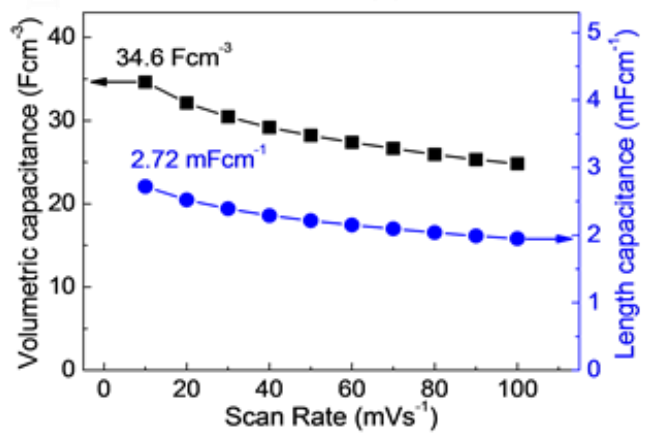

Figure 3 


\section{WILEY-VCH}

A

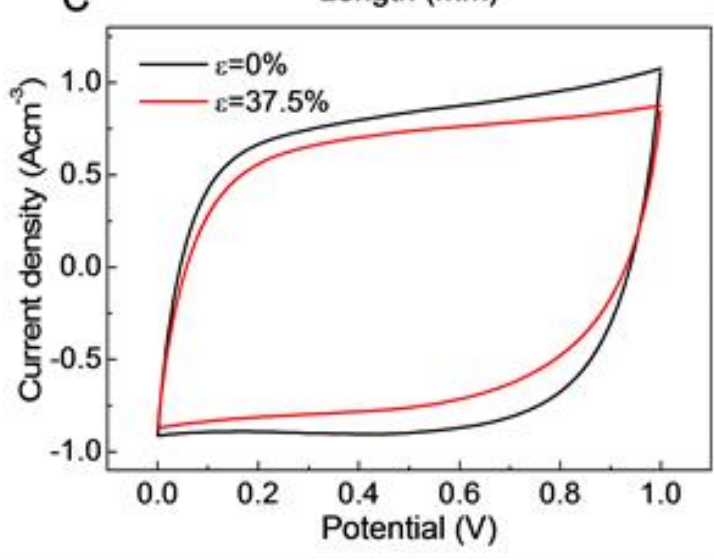

B
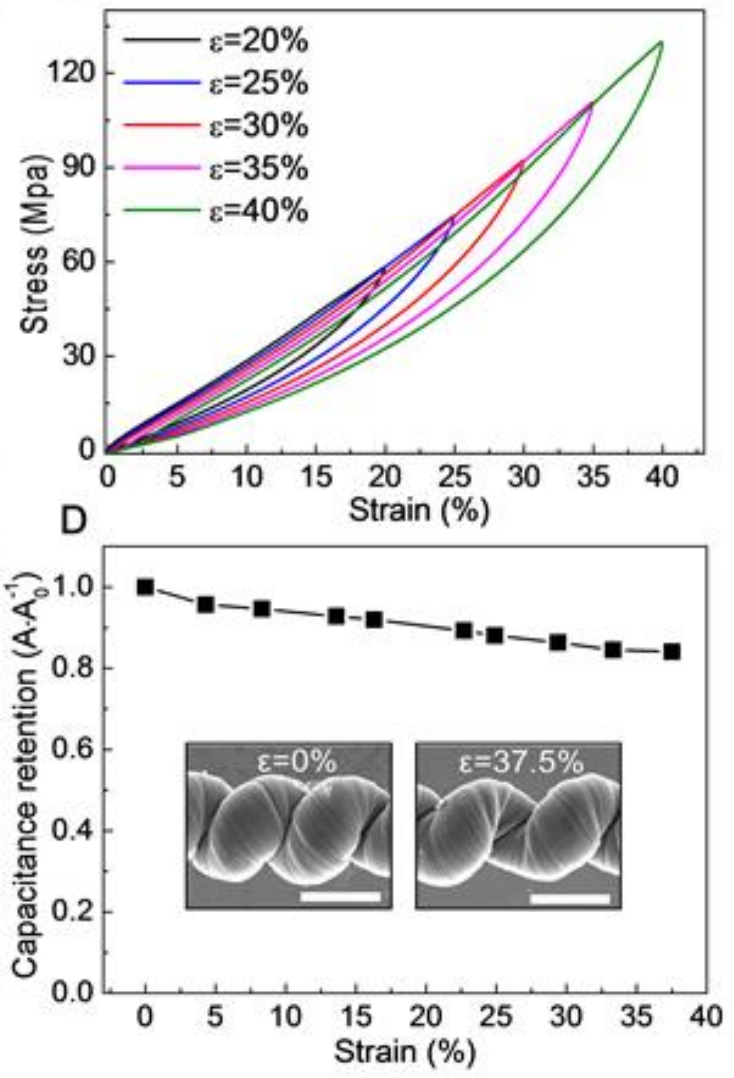

Figure 4 
A
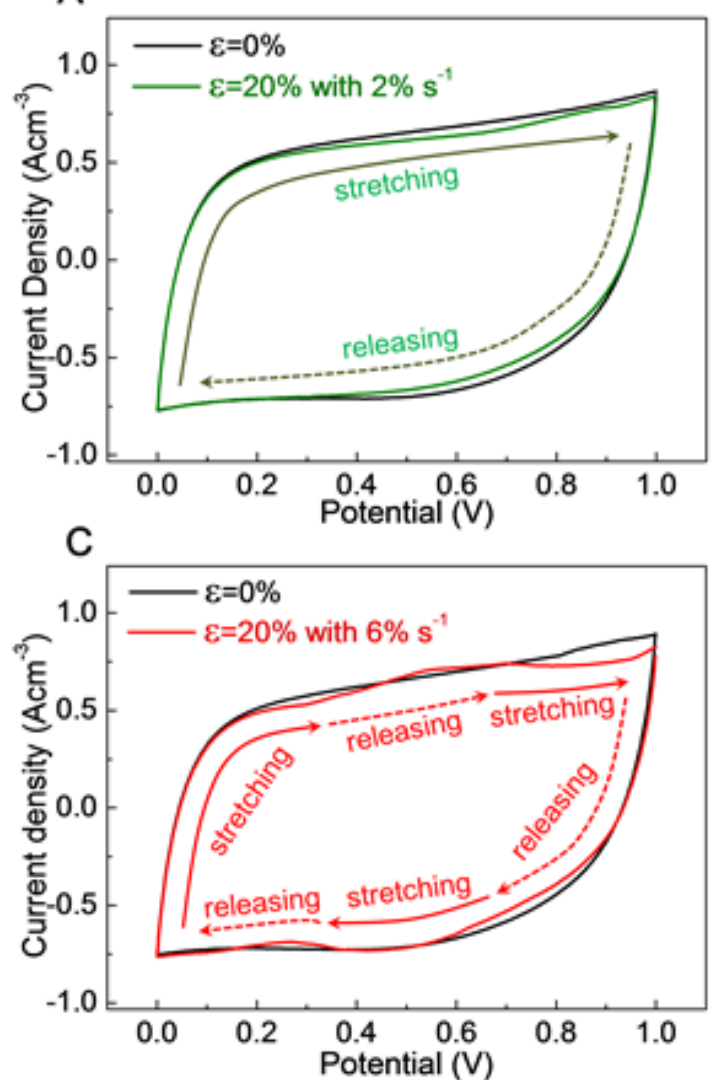

B

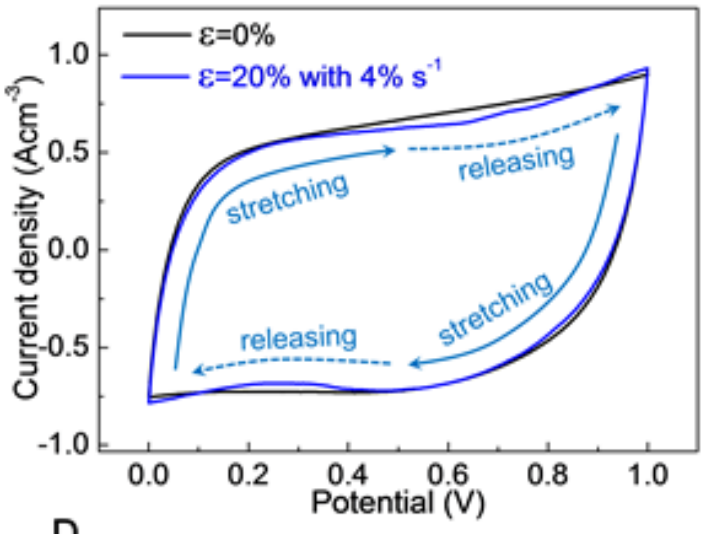

D

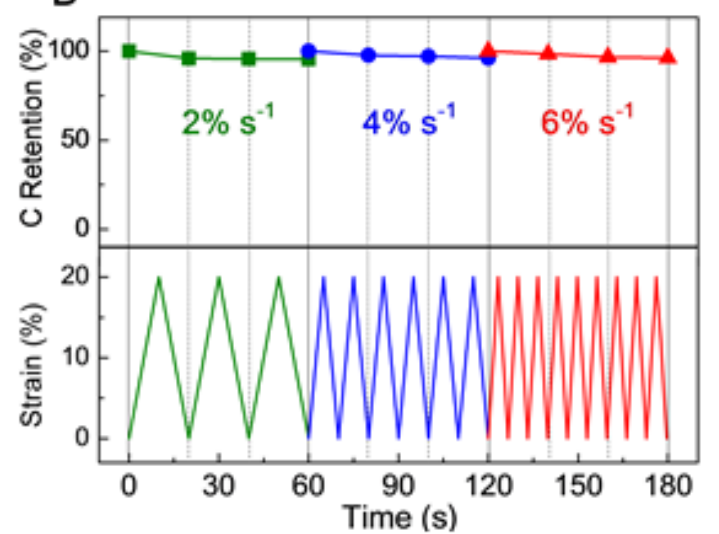

Figure 5 


\section{WILEY-VCH}

Table 1. Specific capacitance comparison of the coiled supercapacitor with reported FBSs.

\begin{tabular}{|c|c|c|c|c|}
\hline Deformability & Electrode Materials (Ref. No.) & $C_{\mathrm{L}}\left[\mathrm{mF} \mathrm{cm}^{-1}\right]$ & $C_{\mathrm{A}}\left[\mathrm{mF} \mathrm{cm}^{-2}\right]$ & Condition \\
\hline \multirow[t]{4}{*}{ Stretchability } & $\mathrm{MnO}_{2} / \mathrm{CNT}$ coiled fiber (Present Work) & 2.72 & 61.25 & $\mathrm{CV}^{\mathrm{a})}$ at $10 \mathrm{mV} \mathrm{s}^{-1}$ \\
\hline & CNT spring fiber (24) & 0.51 & 27.07 & $\mathrm{GCD}^{\mathrm{b})} \mathrm{GCD}$ at $424 \mu \mathrm{A} \mathrm{cm}-2$ \\
\hline & Buckled $\mathrm{MnO}_{2} / \mathrm{CNT}$ fiber (23) & 0.26 & 27.98 & $\mathrm{CV}$ at $10 \mathrm{mV} \mathrm{s}^{-1}$ \\
\hline & All graphene core-sheath fiber (9) & 0.02 & 1.7 & $\mathrm{CV}$ at $50 \mathrm{mV} \mathrm{s}^{-1}$ \\
\hline \multirow[t]{9}{*}{ Flexibility } & $\mathrm{MnO}_{2} / \mathrm{CNT}$ fiber (2) & 0.019 & 3.57 & $\mathrm{GCD}$ at $0.5 \mu \mathrm{A}$ \\
\hline & $\mathrm{MnO}_{2} / \mathrm{ZnO}$ nanowires/polymer fiber (16) & 0.02 & 2.4 & $\mathrm{CV}$ at $100 \mathrm{mV} \mathrm{s}^{-1}$ \\
\hline & Graphene fiber (8) & 0.01 & 0.72 & $\mathrm{GCD}$ at $424 \mu \mathrm{A} \mathrm{cm}{ }^{-2}$ \\
\hline & $\mathrm{TiO}_{2} / \mathrm{CNT}$ fiber (3) & 0.024 & 0.6 & $\mathrm{GCD}$ at $0.25 \mu \mathrm{A}$ \\
\hline & CNT fiber, CNT film (4) & 0.029 & 8.66 & $\mathrm{GCD}$ at $1 \mu \mathrm{A}$ \\
\hline & PEDOT/CNT fiber (1) & 0.47 & 73 & $\mathrm{CV}$ at $10 \mathrm{mV} \mathrm{s}-1$ \\
\hline & Graphene/CNT fiber (5) & 0.027 & 4.97 & $\mathrm{GCD}$ at $0.04 \mathrm{Ag}^{-1}$ \\
\hline & ZnO nanowire/graphene fiber (10) & 0.025 & 0.4 & $\mathrm{CV}$ at $100 \mathrm{mV} \mathrm{s}^{-1}$ \\
\hline & Pen ink/carbon, metal fiber (15) & 1.008 & 26.4 & $\mathrm{CV}$ at $100 \mathrm{mV} \mathrm{s}^{-1}$ \\
\hline
\end{tabular}

\footnotetext{
a) Cyclic voltammograms (CV). ${ }^{\text {b) }}$ Galvanostatic charge-discharge test (GCD).
} 